Elżbieta Kupczyk, Roman Suligowski

\title{
TEMPORAL AND SPATIAL PATTERNS OF HIGH INTENSITY RAINFALLS IN POLAND
}

\section{RAINFALL DEPTH OF SPECIFIED RETURN PERIOD}

In many situations of hydrological practice as design floods estimation at ungauged sites or drainage system projects, the design storm serves as the input element for runoff hydrograph calculation. A design hyetograph specifies not only a rainfall event depth (or intensity), duration and frequency but also gives the time distribution of rainfall depth during a storm. Such information has been given for territory of Poland based on precipitation frequency analysis of 30-year pluviographic records. The intensity - duration - frequency relationships has been developed by analysing annual exceedance series of rainfall intensity set up in 13 duration classes, and by using Frechet's generalized extreme value distribution. The quantiles calculated for events having duration from 30 minutes to 24 hours were performed in form of tables and maps. Figure 1 shows distribution of rainfall intensity for $1 \%$ probability of exceedance for short rainfall $\left(t_{\mathrm{r}} \leq 30 \mathrm{~min}\right.$.).

\section{TYPES OF STORM AND ITS TEMPORAL PATTERNS}

On the basis of physical and statistical analysis of rainfall the conclusion was drawn that series of rainfall events of different duration can not be regarded as the homogeneous statistical process. The main characteristics: intensity, duration and also areal extent of rainfall are determined by various scale meteorological processes. According to different precipitation producing mechanisms the genetic types of rainfall can be identified (Sumner, 1988). Rainfall series could be subdivided on the basis of synoptic maps representing each storm event or by statistical analysis of rainfall characteristics.

The first method requires extensive information and is very time consuming. The most important task in the statistical approach was to identify the crucial characteristics of rainfall events, reflecting the main feature of genetic type of rainfall. After several attempts of both, meteorological and 


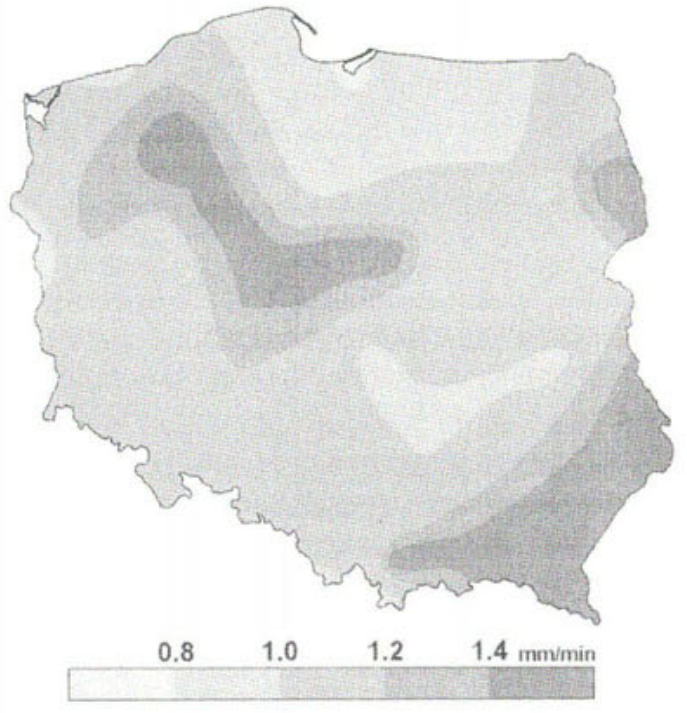

Fig. 1. Rainfall intensity $[\mathrm{mm} / \mathrm{min}]$ for $1 \%$ probability of exceedance for classes of rainfall duration $t_{r} \leq$ $30 \mathrm{~min}$. statistical analysis, it was found that the key characteristic is the functional relation of total depth of rainfall to its time of duration. The example of graph describing depth-duration relationship and subdivision procedure into three duration sectors corresponding to genetic types of rainfall is presented in Fig. 2. Three genetic types of rainfall in Poland were identified.

Convection rainfall, induced by single convection cell or multi-cells convection with intensive ascending and descending currents, characterised by high average intensity of all rainfall episodes having duration from 5 to 90 minutes (sector 1 in Fig. 2).

Frontal type of rainfall - formed a distinct group of rainfall events in Poland, connected with passing atmospheric frontal zones. Rainfall area connected with warm front is very large and relocates slowly thus, long duration rainfalls are of low intensity. A cold front usually relocates faster, processes in front zone occur more dynamic, which leads to a higher intensity of rainfall of the 1.5-5.5 hours duration. Due to the differences of processes acting in frontal zones, an average picture of this type rainfall presents the very diversified characteristics and generally lack of dependence between rainfall depth and its duration.

Atmospheric depression rainfall are connected to the passage of a deep depression including two active frontal surfaces or with large convergence zone in synoptic scale. These types of processes produce of long duration rainfall with altered intensity. In continuous rainfall records observed at sites, a weakened intensity of rain or some breaks occur after passage of warm front. The hyetograph of rainfall connected with passing of whole depression configuration with active fronts system, shows a distinct intensity increase in the duration sector $10.5-24$ hours, caused by intensive rain-inducing mechanisms of the cold front.

The problem of classification of rainfall events according to the genetic types is important in the study aimed at design hyetograph development. Temporal distribution of rainfall intensity is closely related to the genetic type of the events. The temporal patterns of rainfall intensity were obtained on the basis of rainfall episodes classified into the genetic types. Dimensionless cumulative curves of rainfall depth related to the time recorded from its 


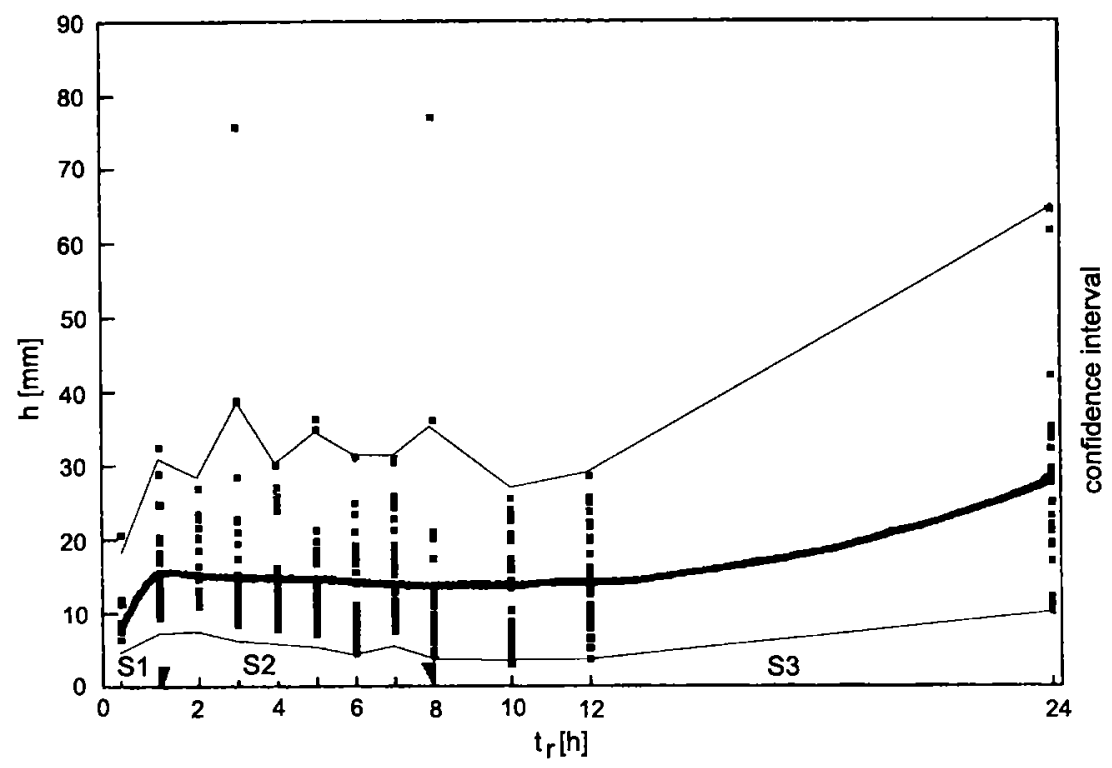

Fig. 2. Maximum depth of rainfall events against time of its duration at Torun.

\begin{tabular}{|c|c|c|}
\hline $\mathrm{S} 1$ & $\mathrm{~S} 2$ & $\mathrm{~S} 3$ \\
\hline $\mathrm{h}=-10.53 \mathrm{t}_{\mathrm{r}}^{2}+20.75 \mathrm{t}_{\mathrm{r}}+6.72$ & $\mathrm{~h}=-0.31 \mathrm{t}_{\mathrm{r}}+17.25$ & $\mathrm{~h}=0.044 \mathrm{t}_{\mathrm{r}}^{2}-0.83 \mathrm{t}_{\mathrm{r}}+18.81$ \\
\hline
\end{tabular}

starting point (in percent of total duration) for convection type and atmospheric depression type illustrates Fig. 3. Analytical form of the curves, as more useful in calculations has been also developed.

The equations enables subdividing a rainfall impulse, described up to now by three characteristics: intensity - duration - frequency into time intervals adjusted to the input of the hydrological models requirements.

\section{REGIONALIZATION RELATED TO THE TYPES OF RAINFALL}

Statistical regionalization comprised two steps procedure. Initial regionalization was conducted to identify the groups of stations with similar characteristics of rainfall intensity for each genetic type. The second stage of regionalization was aimed at evaluation the homogeneity of the separated regions. The matrix of variables has been formed with annual maximum intensity of rainfall lasting $t_{r}<1.5 \mathrm{~h}$ for convective type; $2.5-8.5 \mathrm{~h}$ duration classified as frontal type, and events longer than 8.5 hours for group of depression rainfalls. Geographic variables were represented by: longitude, latitude and altitude of the stations.

Two agglomerative hierarchical procedures (Johnson and Wichern, 1982) were tested: average linkage clustering and minimum variance clustering 
Convection type

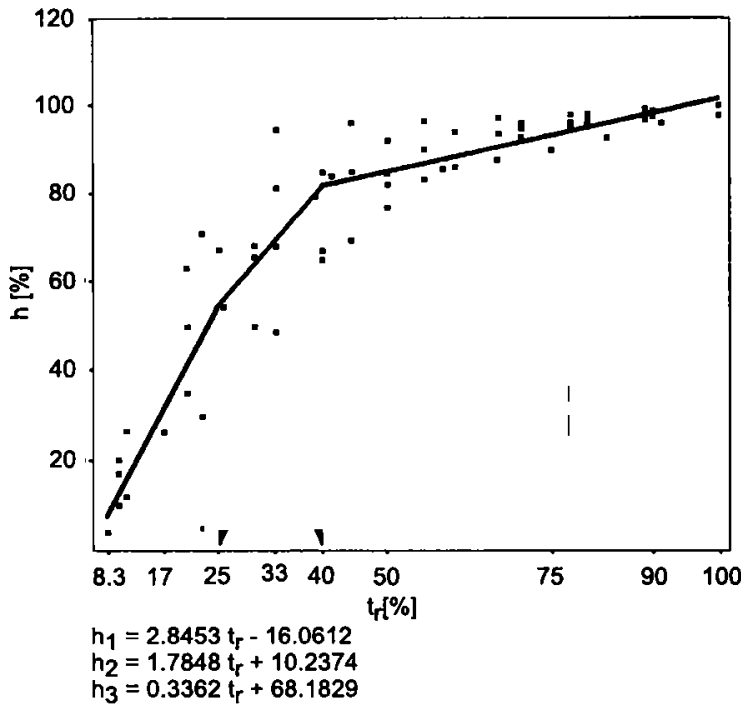

Atmospheric depression type

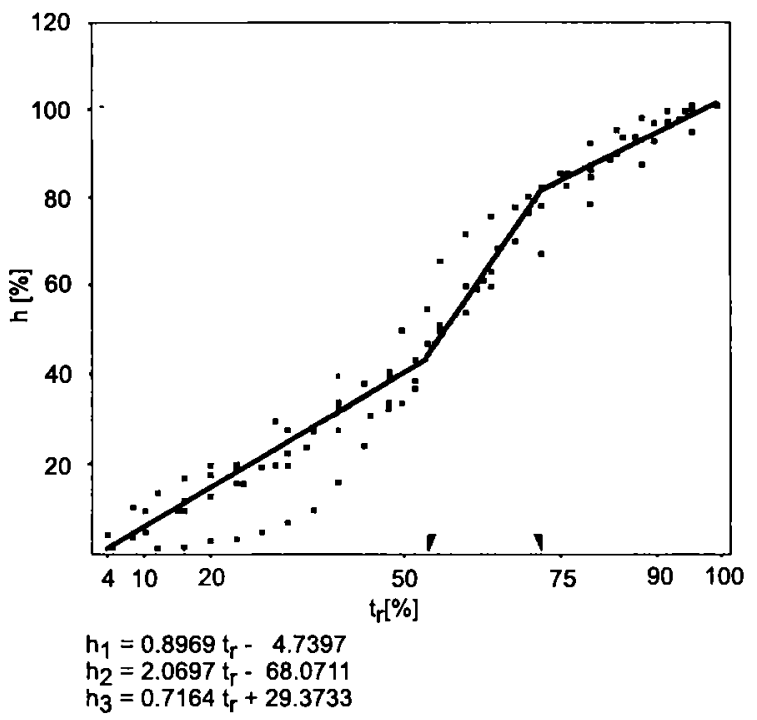

Error of approximation

minimal $=9.525434$

spline off $=\mathbf{9 . 5 2 5 4 3 4}$

spline on $=\mathbf{9 . 8 4 1 9 1 1}$

Division points

$S 1+S 2: 24.80000$

S2 + S3: 40.00000

Confidence level

$\alpha=0.05$

Error of approximation

minimal $=5.354808$

spline off $=5.354808$

spline on $=\mathbf{5 . 8 2 4 3 4 7}$

Division points

S1 + S2: 54.80000

S2 + S3: 72.00000

Confidence level

$\alpha=0.05$

Fig. 3. The typical temporal patterns of storms for genetic types of rainfall.

(Ward's method) to search their usefulness for grouping similar sites with respect to rainfall attributes. Finally, application of Ward's method appeared to be more effective. Decisions about desirable distance levels and number of groups we have taken on the basis of knowledge on scale of processes in each type of rainfall. The grouping procedure and distance levels at which they 
occur in case of convection rainfall are illustrated by dendrogram in Fig. 4. Spatial projection of the subdivided groups outlined 5 regions in case of convection type, and 3 regions related to frontal and 3 for depression type. Maps of the regions is shown at Fig.5a, b, c.

The next step of regional analyses concerns the examination of homogeneity of initially outlined regions. For statistical testing whether the specified group of sites might be treated as homogeneous one and for identification of outlayers, Hosking and Wallis (1993) approach was adopted. Hosking's algorithm for L-moments graphical test, applied to frontal regions testing is shown in Figure 6.

Numerical discordancy measures were established by comparison of Lmoments in sample for the group of sites with those expected for a homogeneous region. To establish "expected" characteristics for a homogeneous region the simulations have been carried out for synthetically generated networks. The result of the tests was positive and confirmed adequacy of subdivided regions with respect of underlying precipitation producing processes.

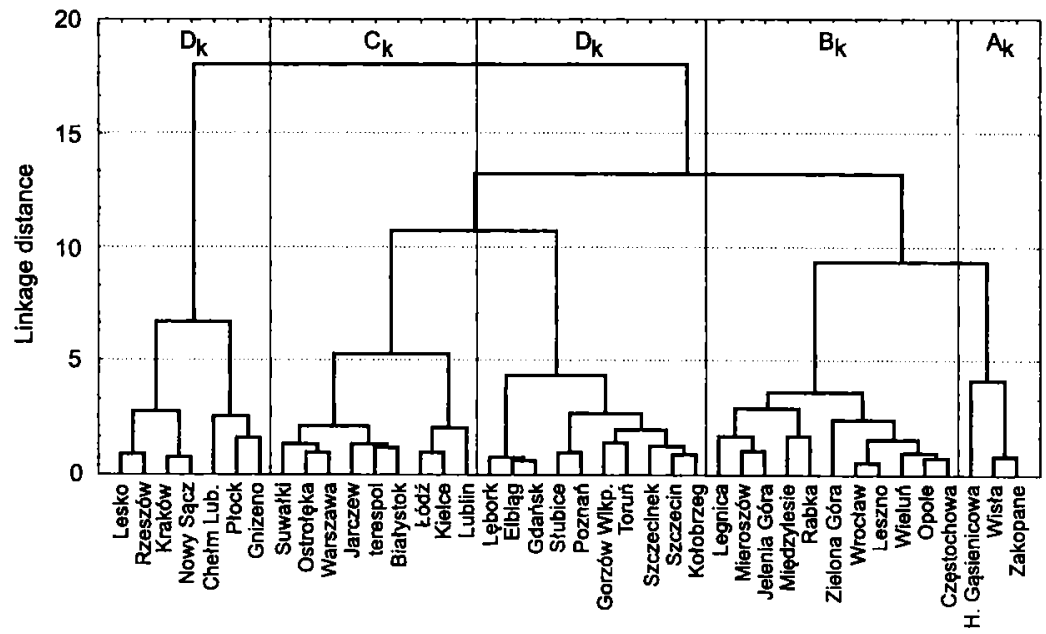

Fig. 4. Tree clustering for convection rainfall in Poland.

\section{CONCEPT OF MAXIMIZATION OF RAINFALL DEPTH}

Application quantiles values of rainfall depth, calculated on the basis of observed series, in many cases does not provides sufficient criteria for estimation of the design floods of very low frequency. This problem involves the necessity of estimation an upper limit of possible precipitation depth in a given region. Such upper limit exists and is termed by physically possible meteorological conditions at particular location and season. 

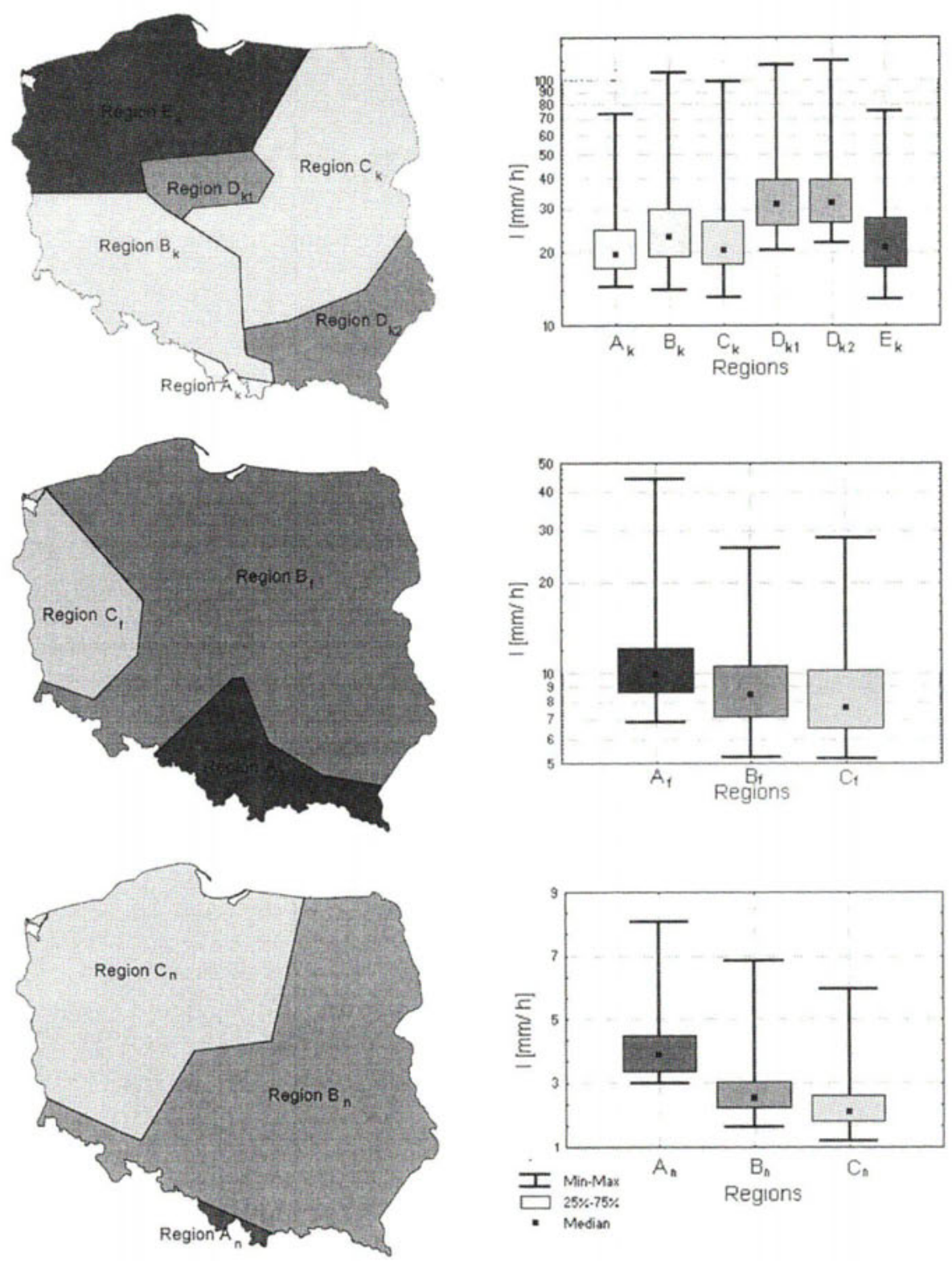

Fig. 5. Pluvial regions for genetic types of rainfall in Poland. (A - convective rainfall, B frontal rainfall, $\mathrm{C}-$ atmospheric depression rainfall)

In the case of convection type of storms (5-90 minutes duration) it is very difficult to estimate maximum possible value based on physical factors analysis. These are very diversified and depend on local processes. Therefore, in the current work, maximum possible values of convective rainfall are de- 
rived by taking maxima of all historic events which have occurred in the region considered to be homogeneous. Having series of largest depth of storms plotted against their duration, the maximum possible rainfall depth may be determined from the envelope of the highest points.

The most important problem for the design of large structures is determining the amount of long rainfall with no risk of exceedance. From several years the south area of Poland is suffered by floods cause by the extraordinary high rainfall. In the Sudeten Mountains the amounts of 2-days and 3 -days rainfall exceeded the depth determined as the values of $1 \%$ probability of exceedance. It suggests that the established values should be revised, and maximum possible values of rainfall depth should be derived by using physical concept rather than the simple statistical extrapolation.

Fig. 6. Elipse of discordancy with respect to L-kurtosis and L-skewness for rainfall region $\mathrm{Bk}$.

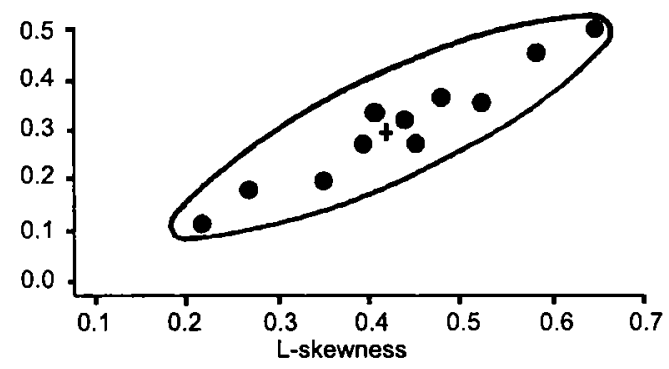

\section{CONCLUSION}

Three genetic types of rainfall were separated from the whole series of rainfall events: convection, frontal and atmospheric depression rainfall. The best statistical criterion which, made it possible to divide rainfall events into genetic groups, turned out to be inflection points at the curve, reflecting functional relation of rainfall depth and its time of duration. The each group of events is connected with different precipitation producing mechanisms, thus rainfall characteristics differ considerably, which can be seen at maximum rainfall intensity quantiles values. The temporal patterns of rainfall intensity along time of its duration are also differentiated.

Two steps regionalization procedure was used in the study. Initial regionalization was aimed at identification the groups of stations with similar characteristics of rainfall intensity for each genetic type. The second stage of pluvial regionalization involved the examination of homogeneity of initially outlined regions and identification of outlayers. The results of the tests were positive and confirmed the homogeneity of the subdivided regions. 


\section{REFERENCES}

H osking J.R.M., Wall is J.R., 1993, Some Statistics Useful in Regional Frequency Analysis, Water Resour. Res., 29(2).

J ohns on A.R., Wi chern D.W., 1982, Applied Multivariate Statistical Analysis, Prentice Hall, New Jersey.

S u mn er G., 1988, Precipitation. Process and Analysis, John Wiley and Sons Ltd., London. 